\title{
I have a garden on the Internet! Searching for the farmer in a remotely controlled farming enterprise
}

\author{
Ernst Michael Preininger ${ }^{1}$ and Robert Hafner ${ }^{2}$ \\ ${ }^{1}$ Department of Geography and Regional Science, University of Graz, Graz, Austria \\ ${ }^{2}$ Department of Geography, Innsbruck University, Innsbruck, Austria \\ Correspondence: Ernst Michael Preininger (ernst.preininger@uni-graz.at)
}

Received: 1 September 2020 - Revised: 4 May 2021 - Accepted: 10 May 2021 - Published: 1 June 2021

\begin{abstract}
The paper examines the conceptual implications of using Smart Farming Technologies and digitalisation in small-scale food production, exemplified by the Austrian start-up "myAcker". The company runs a hybrid system of gamified, remote-controlled agriculture, where its customers assume the role of "online gardeners" and take care of their own vegetables. Conceptually, it combines two different logics, namely the technology focus of vertical farming and algorithm-based control over operational processes, and the participatory, values-based elements of Alternative Food Networks like connectivity, sustainability, and ownership developed by online gardeners. Consequently, the dividing lines between producers, customers, and technology, as well as between virtual and physical, become blurred. Thus, the agency of technology becomes a co-constituent of agricultural work, life, and identity, which is itself co-constituted by human actors in a network of social relations.

The case study shows the new potential and pitfalls of small-scale smart farming and digitalisation, making it necessary to conceptually revisit human-environment relations in the Actor Network Theory by more explicitly including technology as a bridging element.
\end{abstract}

1

\section{Introduction}

The use of Information and Communication Technology (ICT) - data-based tools, digital reflections of natural processes, and control mechanisms determined by algorithms - affects the way explicit and implicit agricultural knowledge is produced on farm and used in day-to-day decision-making. The growing influence of digital technology's logics on social practices fundamentally shifts farmers' work routines and is most likely to culminate in changes and challenges for the whole "epistemological, ontological, and organizational" (Klerkx et al., 2019:7) culture of food production. Visible attributes of farming and the role of the farmer are evolving rapidly; they are in increasing contrast with the image people have in mind about agriculture and farm-related realities.

The manifold dimensions of agricultural food production, whether on an industrial, globalised scale or on local, family farming levels, attract attention of social and rural geography (Paniagua, 2021), Agro-Food Studies (Ermann et al., 2018:96 f.), and the geographies of food (Kneafsey et al., 2021). Theoretical perspectives on technology use and its socio-spatial impacts continuously shape discourses about nature and culture, agency, and identity of farmers and technology, knowledge, consumption, and power relations (e.g. Goodman and Dupuis, 2002; Winter, 2003; Gesing et al., 2019; Kneafsey et al. 2021). Artificial intelligence and accurate algorithms promise to be useful in decision-making and automatisation. Here, in particular, digital geographies explore digital practices with emphasis on reconfigurations of epistemology and the production of space (Ash et al., $2018 \mathrm{a}, \mathrm{b}$ ). The latest technological developments in agriculture, including agency of software and algorithms, trigger a bundle of questions concerning farming expertise and the role of the farmer in the process of food production (e.g. Tsouvalis et al., 2000; Grey and Gibson, 2013; Klerkx et al., 2019).

The most recent agricultural innovations involve a growing focus on the implementation of digital(ised) tools in the form of ICT. By relying on a defined set of indicators, their 
major contribution is to facilitate the monitoring and calculating of influencing factors (operating resources) on the farming process. This involves the use of technological innovations that are subsumed under Smart Farming Technology (SFT). Here, Smart Farming, also known as "Agriculture 4.0" or "Big Data Farming", includes forms of Precision Farming as a scope of utilisation. Scholars and users (as well as technology providers and political stakeholders) fancy the term "revolutionary" in the description of this "digital turn" in the agricultural sector (Bronson and Knezevic, 2016; Walter et al., 2017; Pedersen and Lind, 2017; Sørensen et al., 2019; Zambon et al., 2019; Belafoutis et al., 2020). However, current trends are more evolutionary than revolutionary. They are a sequence of a continuum rooted in historical developments, which have led to another stage of intensification of farming, with no clear evidence of a focus on a greener or more equitable agriculture (cf. Miles, 2019). The technological progression in agriculture certainly carries potential and expectations, both ecologically and economically. Ecologically, farm management based on the optimisation of operating resources and knowledge about farming processes reflected in real-time data streams allows for expectations regarding sustainability and counter climate change action. Economically, developments grant different scenarios, but it is not decided yet who they will serve the most small-scale family businesses or large operations or, in the long run, maybe no-one at all.

In this paper, we want to exemplify the use of ICT for new systemic approaches in agriculture and review critical aspects of this development theoretically and conceptually. In doing so, we refer to the capabilities of software for how virtual and physical realities can be combined in order to raise questions about implications of the shape of future food production schemes. At the centre of our exploration is "myAcker", an internet-mediated agricultural start-up in a rural southern Austrian region which allows customers to manage the cultivation of their "own garden" both virtually and remotely, with real plants on an acre and game-like functionalities quite similar to Facebook's popular online game of FarmVille. The organisational concept shows the following hybrid characteristics: on the one hand, although it is not congruent with the basic principles of Alternative Food Networks (AFNs), there are obvious similarities, as there is constant and direct interaction between consumers and physical producers on the spot, and their roles even seem to be reversed at times. On the other hand, the conceptual and comprehensive use of information technology shows similarities with the Vertical Farm (VF), a highly developed form of maximum controlled indoor cultivation. Furthermore, and as a challenging contrast, the start-up's appearance and transported image serves a clichéd image of "traditional" farming and vegetable cultivation.

To investigate the systemic approaches of this agricultural start-up, we use qualitative empirical data collected from customers and a start-up owner concerning their intentions and experiences. In doing so, we follow the strengths and weaknesses of exceptional farming concepts with a distinctive focus on technological solutions which, like the case of Vertical Farming, is traded as a future hope for food supply on many levels, with the doubtful potential of replacing family-owned farms and farmers.

\section{A garden on the Internet - virtually farming remotely controlled plots}

New niches of gardening, food production, and provision take advantage of the rapid progression of digital technologies and their availability and practicability in private and commercial sectors alike. For example, the company Gardena, Europe's market leader for gardening tools, provides a huge variety for interconnected, remotely controllable products and applications for smart use in private home gardens and, unsurprisingly, in partnership with big tech players, Amazon and Apple, using established cloud platforms (Gardena, 2021). On a much smaller scale, and independently from the giants of the tech industry, the Austrian start-up "myAcker" uses similar technology. myAcker represents a scheme of virtual customer participation that is best described as remote-controlled gardening or farming. From an entrepreneurial perspective, the start-up represents an attempt at digitally commodifying private gardening - a recreational activity which is not usually organised in conformity with the market logic - and running it as hybrid agricultural start-up with online and offline dimensions and technosocial, as well as private and commercial, aspects.

In its fourth season, the agricultural tech business run by two young locals and their two employees, one of which is a vegetable gardening specialist, has over 2200 active customers (myAcker, 2020). Located in the rural municipality of Mühldorf in southern Austria's federal state of Carinthia, in an intra-alpine basin surrounded by grassland and arable economy, the start-up has developed a business model that provides online users with "their own" physical plot of farmland. Personal parcels extend in several lines over an area of about 6 ha (see Fig. 1) and can be cultivated remotely by customers via a web app. Options range from the choice of plants, fertilisation, and watering to harvesting on time, which are all carried out in situ after the task is ordered on the web app. However, the amount and intensity of customer action are both limited by the providing company and by technological restraints; only a restricted number of crops can be chosen for cultivation, and only one type of plant may be grown on one plot. Once the plants grow on the customers' plot, data on weather conditions, temperature, or soil quality are generated on the spot and fed to the company-specific algorithms. The result of the data interpretation is then visible on the customers' digital screen, pre-selecting and limiting the decision possibilities in a user-friendly manner. If the soil is too dry, the customer is notified by a colour-coded 
suggestion board where he or she can decide to have the plant watered.

The underlying idea of myAcker is quite similar to, but much more elaborate than, a case that has been described by Holloway (2002), who explored an internet-mediated participatory business model in southeastern England that also rented out agricultural plots or virtual gardens and had customers suggest interventions in the growing process. Major technical constraints back then kept actual customer participation to a minimum, thus being restricted to a preliminary stage of remote-controlled gardening. Although customers could give instructions, the response to their input was very limited; prior to the dispatch of the weekly home deliveries of goods, they received a written report along with a photograph of their personal garden plot. While the degree of customer satisfaction in Holloway's (2002) case remains unclear, the narrative is reminiscent of our case study example, i.e. "You are growing your own vegetables, and you always know exactly where they are. You are in control; you decide, and we are getting our hands dirty ... Fresh vegetables from your own field, no matter where you live or what you do" (myAcker, 2021). Technological advancements and the availability of relevant data have, however, since facilitated many more options for digital interaction between customers and their plants. On their website, the start-up regularly publishes the activities of the gardeners in their field, for instance (names are changed), "Brigitte has consistently and carefully ploughed 'Brigitte's Garden", or "Karl has carefully weeded his parcel on the field".

In contrast to other, "classical" uses of Smart Farming Technology (e.g. field cropping using typical machinery with serial workflows), the system of remote-controlled gardening bears unusual implications for both producers and consumers as the latter play an active part in (preselected) decisionmaking on production. We, thus, argue that the transfer of parts of the farming or gardening responsibility turns consumers into producers too.

At this point, the following two dimensions need to be separated: actions and discourse. On site, the actions and tasks usually carried out by a farmer are increasingly automated. Even today, neither does the production site of the start-up look like a farm, nor does it work like one. For example, the visible physical operating procedures are more reminiscent of an Amazon warehouse - employees drive from plot to plot, apparently at random, in order to perform individual tasks as requested by plot tenants. To better understand the functional roles and mechanisms of technology used in myAcker's production process, we create an analogy to the classification of SFT by Belafoutis et al. (2017:23). They offer a useful framework by outlining a general typology of SFT, according to their application in the farming process, divided into three main groups. The first group is comprised of data acquisition technologies, which are at the front end of production practice on-farm, responsible for collecting, recording, surveying, mapping, navigating, and sensing of relevant data for further on-site use. In the case of myAcker, every phase of the growth is monitored to collect information for further processing. Sensors report background data, including temperature, soil moisture, wind speed, precipitation, luminous intensity, pest and weed infestation, and growth progress. In situ webcams provide live views of the field.

The second group refers to data analysis and evaluation technologies, which are decision-supporting technologies that use modelling processes based on available data (accumulated recorded and real-time data), apps, or whole farm monitoring and management information systems (FMISs), representing an interface for relevant variables to be displayed on mobile devices. We consider the function of this type of technology in the realms of nudging, since data gathered from these systems (indicating, e.g., a lack of humidity and nutrients in the ground) is then processed and translated into a binary traffic light system. This translation of the analysed data is a nudge to the gardeners to create a feeling of active participation. If the customer does not react to the suggestion of urgent action, the company does not move - with the ultimate consequence that the plants may die.

The third group consists of precision application technologies that focus on variable-rate application adapted to individual needs (e.g. application of fertiliser or manure or feeding robots) and guidance technologies for machinery (e.g. tractor GPS and linked tools). The outline of the concept is predestined to work autonomously in the future. Building on the functionalities of the first two steps, at the moment, actual tasks on the field are carried out by myAcker employees. The whole organizational set-up is designed to minimise human labour and, where possible, move to automated machinery since completing all the various tasks on each plot in a timely manner necessitates considerably more individual trips than on a regular field.

Moving to the discursive dimension, myAcker's marketing concept and visual statement strictly emphasise traditional growing methods and handcrafted produce. $\mathrm{A}(\mathrm{n})$ (invisible) farmer, teamed up and connected online with end users in their homes, is cultivating vegetables on his or her acre or garden, and is dedicated to regionality. Not necessarily a contradiction, but quite noticeable for the work of a tech startup, the proximity to nature and naturalness is highly emphasised (cf. myAcker, 2021). Hence, technology changes the way how vegetables are grown, while a traditionalistic picture of a farmer is still dominant in the marketing scheme. In March 2019, on Facebook, the company announced the start of a licensed version of their business idea in the Netherlands. "Mijn Boerderijtje", which means "my little farm" in Dutch, was opened in Woudenberg near Utrecht. According to C. (name withheld), one of the owners and inventors, "Mijn Boerderijtje" uses hard- and software as well as logistical solutions provided by myAcker. In a remarkable statement in the Dutch magazine Biojournaal in 2019, the Dutch company owners claim to be "a local and social initiative" and to 

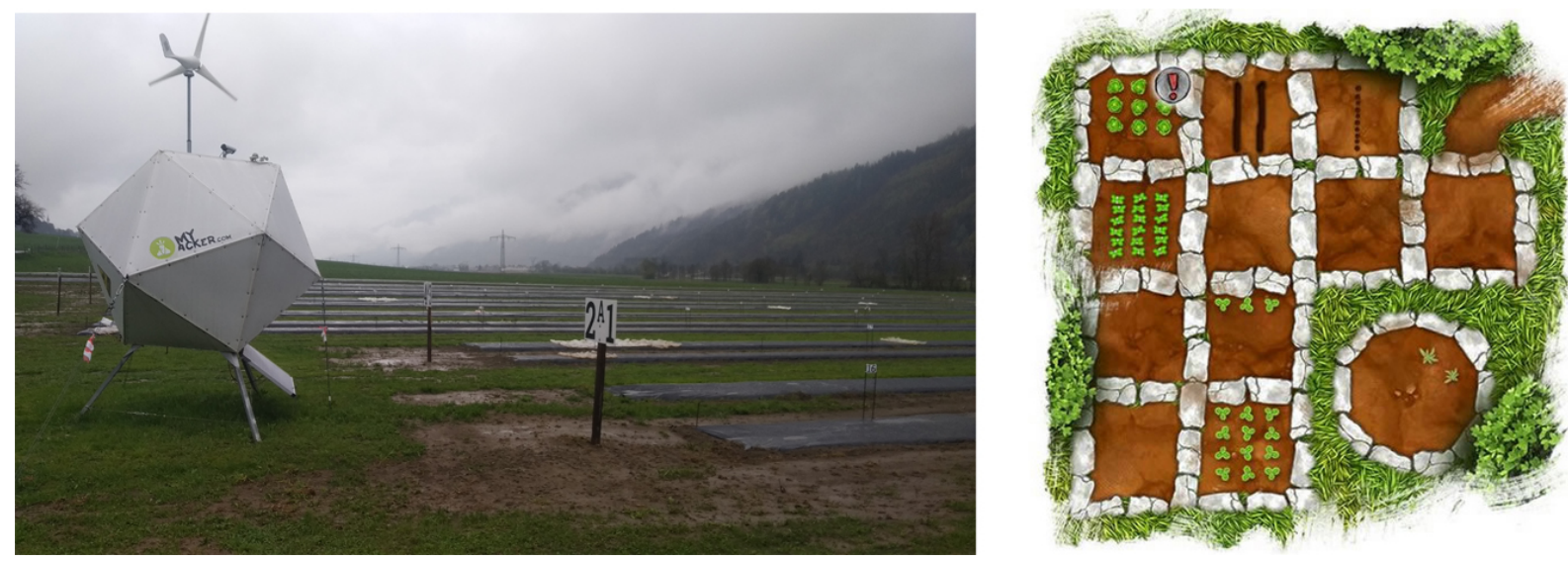

Figure 1. View of myAcker plots and data processor unit (left panel - own photo, 2019) and the virtual representation of the plot (right panel - screenshot from myAcker, 2021).

have the ambition to be the "farm of the future", where "craft and innovation go hand in hand", "first regionally, then nationally and, finally, globally" by providing people the comfort of growing "their own $100 \%$ organic vegetables from the comfort of their own sofa" (all translated from Dutch, Biojournaal, 2019).

The focus of this paper is on the Austrian original. Before we delve deeper into the empirical case study, we turn to positions which contribute to a broader understanding. First, we theorise about the constitution of a farmer in the contemporary context of family farming. Second, we take the theoretical perspective of ANT into account. Third, we observe the relations of the case to AFN and Vertical Farming.

\section{Family farming, the "digital turn" in agriculture, and technological potential for systematic approaches to food provisioning}

In this section, we first discuss the significance of family-run farms and the role of a farmer in the context of recent technological developments. As SFT and ICT have the potential to serve as substantial support for any kind of farm business but, due to their unclear implementation development scenarios, inherently contain threats to common understandings of farm work and farming profession, interrelations are to be disclosed. We use our case study as an example of how technological progression has the potential for new approaches to food provisioning and phenomena, which challenge the understanding of the role of a farmer.

Approximately $90 \%$ of agricultural businesses worldwide are run by individuals or families, accounting for almost $80 \%$ of total food production (FAO, 2014). The concept of family farming does not have a universal definition but includes levels of family income generation, family labour and management, and size limits up to which a farm is considered family-run (Lowder et al., 2016). Austria's moun- tainous topography limits arable land and, in most alpine fringe regions, favours small-scale family farms. Similar to developments in other industrialised countries, technical progression, globalisation, and scale effects, among other reasons, still made way for structural changes. From 1960 to 2013, the number of farms with a farm size of less than 10 ha in total decreased by more than three-quarters, and their share dropped from $64 \%$ to $35 \%$ (Groier, 2016). In total, farm numbers decreased by $59 \%$ (Statistik Austria, 2016). This development has the potential to jeopardise the multifunctionality of rural areas (cf. Wilson, 2001; Murdoch, 2006; Redepenning, 2009). Besides producing food and food-related goods with market relevance, family-run agriculture generates non-commodity outputs in economic, social, and environmental dimensions (van Huylenbroeck et al., 2007: 16-21; Sinabell, 2003: 248 f.). The preservation of cultural and moral values, the maintenance of village communities, regional food security, ecological conservation practices, or biodiversity, among others, are connected with agriculture. Some of these effects are historically grown and not necessarily properties of agrarian production scenarios, but regional entanglements of family farming are undeniable and, in many cases, valuable to rural communities.

But what makes a farmer in today's agriculture? The common understanding of what a farmer's profession and the act of farming encompass is being challenged by the establishment of new behavioural and social contexts triggered by ICT. Previously, all input into the farming process was manual labour intensive, and decisions were based on the experiential knowledge of the farmer (cf. Kritikos, 2017). In the contemporary context, input-intensive farming (cf. Knierim et al., 2019) means investment in interconnected digital technology. The enormous annual growth of ICT capabilities, based on data storage and computational capacities (Hilbert and López, 2006), clearly reveals a variety of potential for different life spheres. ICT influences the way people work, 
provides new options for learning, is capable of improving social and economic development (Thapa and Saebø, 2014; Dasuki and Abbot, 2015), and fosters perceptions of a higher quality of living (Nevado-Peña et al., 2019).

Day-to-day work on farms also benefits from the growing capabilities of ICT. The concept of Smart Farming has great resemblance to industry 4.0 by realising the fundamental idea of the Internet of Things (IoTs). By combining physical with digital technology and its potential in analytics, the learning capabilities of artificial intelligence, and the interconnectedness of ICTs, a data ecosystem is created, upon which profound support in decision-making can be provided (cf. Janc et al., 2019:2). The application of SFT is strongly driven by expectations regarding the alleviation of workload, improvements in economic status, and the belief of being provided with better chances in the free market competition (cf. Zambon et al., 2019; Belafoutis et al., 2017). However, due to high investment costs (e.g. discussed in Knierim et al., 2018), SFT is suspected to privilege larger farm structures and is producing secondary effects, such as standardisation or concentration of space and capital, or the marginalisation of core values, such as animal welfare or autonomy (cf. Klerkx et al., 2019; Stock and Forney, 2014; van der Burg et al., 2019). To prove useful for small and medium businesses in the long run, even distribution of Big Data application benefits actors and up-to-date policies (cf. Fleming et al., 2018) are necessary. Yet, the extent of potential social and societal consequences of game-changing technologies in food production on day-to-day farm work, on related professions, and on private life is unclear. Until recently, the focus of digitalisation research on human living and working spaces has been more in the urban environment. Critical research on Smart City concepts have gained much attention (Murgante and Borruso, 2013; Lombardi and Vanolo, 2015; Bauriedl and Strüver, 2018; Sharifi, 2019), and the production of urban spaces by the agency of software and the spatiality of code has been pointed out (cf. Kitchin and Dodge, 2011). Agrofood systems which underly the same procedures and are in constant exchange and interdependence with cities must not be excluded from this critical evaluation. Jérémy Forney sees three critical areas of change provoked by SFT, i.e. "the relations between human and non-human (animals, soil, etc.) agents; the place of human knowledge and work in providing for sustainable subsistence; indeed, the nature of one of [hu]mankind's oldest links to nature - farming" (Forney, 2018:10).

Some downsides of technological advances in agriculture are moving in from the back door, but they are neither new nor unexpected. Kritikos (2017) points out that a number of socio-ethical risks and challenges result from a growing dependence on third-party influences (such as tech companies) and the complex task of data management and data security, with a growing tendency to treat farmers as information tools rather than subjects with their own capacity to make intelligent decisions. These challenges are a threat to the control over the on-farm production process and to farmers' autonomy. As noted in current debates about Smart Cities, "intelligence [...] is not expected of citizens but of surveillance technologies" (Kropp, 2018:38; own translation). In Smart Farming, by analogy, intelligence is expected of learning machines rather than farmers in the form of seemingly superrational choices based on algorithms (i.e. "algorithmic rationality"; Miles, 2019:5) and pave the way for even better algorithms and more automatisation; they, thus, produce their own systemic logic (cf. Kropp, 2018:36) and increasingly complex decisions become difficult to be traced and comprehended by humans. The farming profession, thus, requires an additional set of skills. For instance, basic knowledge of programming and algorithmicising, robotics, and background knowledge about Big Data problematics clearly reach beyond the typical competencies and task areas that farmers were assigned to in pre-digital times. Here, theoretical perspective ANT (Actor Network Theory; cf., e.g., Callon, 1987; Murdoch, 1997; Whatmore, 1999; Latour, 2007) offers insights into the changing (and fading) of the lines of demarcation between the material and the social. From this perspective, technology is performed; it does not merely hold meanings assigned to it in a functional sense but also takes part in social relationships as a constituting actor. The coconstitution of agriculture and rural agricultural lifestyles by humans and non-humans, culminating in the building of new alliances, thus has the potential to fundamentally change the way agriculture is practised (cf. Bear and Holloway, 2015). In the context of myAcker, technology has assumed the role of the intermediary in a socio-material framework of human and non-human actors bound together in a continuum of work procedures. Alongside material non-human actors (e.g. vegetables, sensors, computer hardware, machinery, and transportation units), virtual-symbolic representations are also part of this fabric.

Conceptually, myAcker and Vertical Farming (VF) share a similar focus on technological implementations as a means of maximised control and the non-relevance of a human farmer (in the family farming sense). Here, vertical means horizontal stacks of layers inside urban indoor facilities, cultivated in laboratory-like controlled conditions, aiming towards sustainable resource management and increased food production through a strong focus on recycling resources and yearround harvests (Despommier, 2010; Kalantari et al., 2018; Beacham et al., 2019). The concept is simple but still technologically complex. To gain maximum control of all input factors (humidity, light, nutrition, temperature, etc.) and to keep the venture financially and energy efficient, it relies on specialised software-controlled mechanisms and algorithms. Among the above-mentioned factors of increased yield and optimised energy flow, the advantages of this systemic approach include transport and land use savings, as well as high-quality produce (Benke and Tomkins, 2017:17 f.). Surplus social value can be generated for the local population in the form of supply with fresh food and local jobs. 
However, VF needs a highly skilled workforce (Benke and Tomkins, 2017:19, 22), engineers, (bio-)technologists, biochemists, marketing specialists, and maintenance workers but no farmers. Finally, it comes down to automatisation. VF aims to create the perfect controlled environment suitable for implementing robotic-based and self-learning cyberphysical systems (cf. Gnauer et al., 2019), which is also a structural aim in myAcker's remote-gardening scheme.

More community-oriented systemic approaches in food provisioning, like community-supported agriculture (CSA), producer-consumer co-operation, farmers' markets or independent farmers' associations - all sharing AFN practices (cf. Goodman et al., 2012) - also benefit from the technological progress of ICT. Online spaces and virtual representation open up new opportunities to realise a key objective of AFN, i.e. the (re)connection of citizens with processes and components of food systems. In its capacity for interaction related to social media, these spaces connect the physical, local, and time bound with the timeless, nonphysical, and virtual (cf. Holloway, 2002; Bos and Owen, 2016) and offer easier disclosure and, hence, diffusion of knowledge (Randelli and Rocchi, 2017:99). The emergence of direct networks between producers and consumers have been described as an alternative to "... the more standardised industrial mode of food supply” (Renting et al., 2003:394).

Here, the underlying idea and practice of myAcker shows parallels with AFN, offering alternatives to the industrial agribusiness, conventional food supply, anonymity, or market logics. Core AFN topics reach from connectivity (direct relations between consumers and producers and participants), to sustainability (organic production, eco-friendly practices, and high-quality produce) to proximity (short distances, direct trade, close linkage to production process, and local embedment; cf. Michel-Villarreal et al., 2018). All of the above are attributed to myAcker's model too.

The blurring of a clear dividing line between the producer and consumer and the establishment of direct interconnection between the two reflect the attempt to eliminate intermediary trade and to walk new paths. Web application tools and mechanisms to actively guide the cultivation process, combined with first-hand information from the field nourishes (feelings of) proximity to place and conditions of production. The narrative and commitment to "natural" and organic cultivation and the transfer of agricultural knowledge once kept by grandmothers refers to sustainability attributes. myAcker minimises its production-related risks by transferring parts of the responsibilities for the success of producing "their" food to customers, thus individualising the risk of crop failure. In CSA, the producers' risk is also reduced by putting it on the participating community. Although myAcker shares properties like participation with AFNs, the aims for doing so differ greatly. The start-up is not run by a farmer and is focused on streamlining technology to automate a business model and make it as efficient as possible, whereas AFN focus on their socio-ecological impacts and the concept of values-based supply chains (Plank et al., 2020:51).

\section{The case of myAcker as a new approach to food production and its consequences}

In this chapter, we approach the topic from the statements of the start-up owner C. and relate his ideas and narratives to experiences of their online gardeners or customers. In April 2019, the production site in Carinthia was visited for field observation. With C., a qualitative, semi-structured interview was carried out face to face on the same day. After this, in July 2019, a semi-standardised online survey, with 203 participants, was conducted among active myAcker customers. The survey consisted mainly of open questions about experiences, preferences, and motivational aspects relating to the use of myAcker. Also, standardised questions about socio-economic background and geographical origin for statistical value were included; the majority of the survey participants and online gardeners are female $(64.95 \%)$, the users are between 30 and 49 years of age $(54.68 \%)$, live in Austrian cities $(54.64 \%$ in one of the 15 statutory cities), and have a tertiary education $(39.41 \%)$.

A total of three main findings from the field study are identified. First, it shows myAcker's apparent contradiction to the frequent reports (cf. Fleming et al., 2018; van der Burg et al., 2019) that Smart Farming applications are considered a tool in which, due to scalar effects, power imbalances and the uneven distribution of benefits mainly serves larger, industrially organised enterprises. Second, digital representation and virtual interaction with a distant plot of land still led to the perception of great closeness and connectedness to the place of production and the produce. And, third, the latest technology is used by the start-up's owners to uphold "traditional" values they have learnt from their grandmothers.

\subsection{Scale, flexibility, and independence of on-farm ICT}

As already addressed in Sect. 3, SFT and digitalisation are often seen as drivers of farm size expansion and upscaling. myAcker has a different goal; farm size expansion is not in the foreground but rather the increase in flexibility and the reduction of investment costs for small enterprises and independence from external software providers. myAcker's owners have programmed their own software and algorithmic structure and are, thus, quicker to adapt their software to their actual needs. This particular flexibility - and simplification - of work offers new opportunities for smaller farms to be profitable.

I am thinking that is it probably a model for someone who says, 'Ok, I have inherited a farm [...]'. It's not rocket science, it's technology, and what it executes. ... He doesn't need a tractor; he doesn't need large farmlands. But it may be a possibility, 
as he says, 'I can maybe revitalise my farm and maybe also generate an income and work flexibly. [It is not so relevant] whether I go planting at six in the morning or four in the afternoon, or I don't know, maybe not in the midday heat, but I can work according to my own schedule'. (Interview with C., 11 April 2019; own translation)

The simplification and flexibility of work through the implementation of technology is also reflected in the discursive representation myAcker's operation model. As a tribute to the small-scale focus, myAcker uses terms like "agriculture"or "field" and "garden" or "farmer" and "gardener" interchangeably. "You own a vegetable garden on the Internet ... Fresh vegetables from your own field for everyone, no matter where you live or what you do! ... Rent and maintain your garden on the Internet and harvest real vegetables! ... Your farmer will then send you a photo of your plot [...]" (https://myacker.com/de/, last access: 8 July 2020; own translation). The blurring of terminologies already indicates a shift in the understanding and perception of a farmer's profession and the underlying methodology. According to C., one of the main strengths of their concept ironically lies in the fact that they are not farmers by profession. However, for this very reason, they manage to do a few things better than in "traditional" agriculture.

We just notice that the big advantage is that we can think well in both directions. I can dig holes, but I also know what a programmer does. I know how databases are constructed; I can't apply it, but I can think my way into it, but, at the same time, I can drive a tractor.... We don't want to make 'agriculture' more efficient - others can do it better with these drones, and whatnot, and land optimisation. In the end, it's all about establishing a relationship with the product and offering prospects. (Interview with C., 11 April 2019; own translation).

\subsection{The disappearance of the farmer - connectedness and ownership of customers}

A goal of the start-up is bringing consumers closer to the product and its production conditions (interview with C., 2019), leading to the second observation, which concerns the establishment of connectedness and ownership between online gardeners and "their" produce. The creation of a closer relationship to remote but physically existing products by digitally alienating the nature of vegetable growing in the most artificial way seems paradoxical at first. The erasure of geographical distance, however, is an essential characteristic of Internet-based (communication) tools, which allows the illusion of proximity between consumer, the provider (as there is no "farmer" to be seen), and the product to the production location. The relationship between digitalisation and society is co-constitutive. Musik and Bogner (2019:6) note that the concept of digitalisation "already contains the social as well" and that "digitalisation is considered a phenomenon where the social and the technical meet and where social practices of development, discourse, norms, and use and the order, arrangement and infrastructures of the digital ... constantly coconstitute each other". Customers refer to food from the myAcker plot they are virtually taking care of as being "home grown".

I think the idea itself is great in that you can have your own vegetables via a quasi-online game. This will surely give some people more connection to a real garden and vegetable growing (FB73).

With a little effort you can have home-grown vegetables (FB78).

I am happy to finally have my own pumpkins and cucumbers (FB102).

myAcker is a great opportunity for busy working people to grow and seasonally cook their own vegetables (FB91).

Good implementation, good product choice, [and] homemade. (FB95).

Today I already weeded and watered... We look after a garden in Carinthia - our own garden (FB104)! (2019; own translation)

Here, mechanisms of participation are translated into a game-like atmosphere; this form of gamification provides the transfer of knowledge in a fun, educational manner (cf. Szilágyi et al., 2017; Martin et al., 2018). The "coding of agricultural processes and practices into software" (Klauser, 2018:371) requires algorithmising and "indicatorisation", the reduction of visibility to selected parameters only. Although customers may acquire some basic knowledge about the cultivation of vegetables with myAcker, learning spheres, like visceral, multisensory experiences of gardening or the physical labour, are denied to the remote gardeners. All these elements are, however, an acquired experiential basis for learning and improved decision-making. Another socio-ethical effect resulting from a limited action corridor predefined by indicators and algorithms is the decrease in opportunities for exploration and experiments. The elimination of coincidentally produced insights and knowledge blocks the discovery of new approaches or solutions. The first sensual or physical experience customers have with their produce is when it arrives at their doorstep - proof that it was not only a game they have been playing. Viewed from a different angle, myAcker does not only sell a final product but commodifies every step of the production process (cf. Lioutas et al., 2019:6), i.e. the growing and taking care of the plants, the connection of the customers to "their" vegetables, the user's being a farmer or gardener, and the game-like setting. 


\subsection{Physical decoupling from and virtual recoupling with traditions and nature}

The third point of interest is the combination of myAcker's focus on "tradition" and "values from the past" through production methods that are far from "traditional" (in the sense of being culturally passed on). Discursively, learning from nature, i.e. the connection to nature and the recognition of natural processes (like the seasonality of outdoor cultivation), is considered as being "traditional" elements that are integral to the company's philosophy (interview with C., 2019). The balancing act of conveying values and knowledge about seasonality and regionality through the non-place-based virtual platform shows the powerful role of technology.

... But strawberries. It's not meant to be this way; the customer should notice, 'Oops, it's just not strawberry season'. He has forgotten that over the years because the retail trade has taken it away from him, but now maybe he's learning it again somehow. And these are things that my grandma taught me... Basically, what we're doing is taking a step backwards. Going back with the new technology. We use the new technology to show what my grandma taught me. And this is also the social development that I think is needed a little bit in the world. (interview with C., 11 April 2019; own translation)

The goal here is to dissolve the division of human vs. nature through technology in the form of the virtual platform. The case study contributes to the debate in Agro-Food Studies that going back to "nature" via technology is indeed possible, supporting the argument of Ermann et al. (2018:120 f.) that a reverse development concerning the use of technology is not likely to happen. Through personal involvement and transparency regarding myAcker's production location and its operators, a feeling of connectedness to their agricultural parcels and ownership of work, place, and product is established among customers. Many consumers have a desire for their consumption to be linked with production because involvement and knowledge about production conditions are often associated with ethics, morale, and quality (Holloway, 2002:71). In some parts of the "alternative" food economy, particularly in the solidarity economy, the emphasis on personal closeness to the producer often leads to value conventions that strongly focus on circulating stories and narratives built on emotional content. Such conventions lead to a shift from objective criteria regarding quality to a quality of relations or, put another way, to a shift from the product quality to the quality of the producer (Varga, 2019). The focus on relations and the sensation of being part of something good particularly holds true for some myAcker customers.

We know where the vegetables come from, and the taste of supermarket goods does not compare (FB159).
A sustainable, organic vegetable garden in Carinthia that I can look after online (FB38).

It's not for people with a small budget, but it's a great way to be in touch with the activity, to support regional farmers, and to make a contribution to climate and environmental protection (FB154).

An alternative way to grow and cultivate healthy vegetables. The costs are a little higher (FB60).

Additionally, almost half of the customers who were surveyed $(47.79 \%)$ are convinced that they are participating in a climate protecting production scheme. More than two-thirds assume that they are contributing to sustainable agriculture, and around $78 \%$ believe that they are strengthening regional agriculture, although parcels with harvested vegetables of myAcker are being sent across the whole country - sometimes across hundreds of kilometres.

\section{Conclusions and outlook}

This paper has presented an example of food production, where "online gardeners" remotely and virtually manage agricultural plots in a game-like setting. Based on real-time data from the agricultural site and algorithms, customers are nudged to press buttons to order tasks like watering, pest management, or fertilisation, which are then carried out by myAcker staff on the spot.

In this farming scheme, no single farmer can be identified. In this community-like agglomeration, customers, startup operators, and "smart" technology are all contributing to the farming process by taking part in collaborative production. A total of two essential thematic complexes stand out. First, the agency of technology is a co-constituent of agricultural work, life, and identity, which is itself co-constituted by human actors in a network of social relations (cf. Bear and Holloway, 2015). Visual similarities of systemic sequences to Amazon warehouses show reversibility of roles of humans and technology; technology takes over planning and decision making, and humans become part of a toolset for tending plants.

Second, food is not the central commodity - it is the active, social aspect of participating in a gardening or farming process, making the intermediate step of retail or farmers' markets unnecessary. Here, the overall layout clearly resembles ideas of AFN and vertical farming. AFN benefits from the progression of ICT for communication, organisation and standardisation. In areas like connectivity to producer and production, sustainability, cooperation, and overall "alternativity" of the supply and producing approach, myAcker is an extreme example of how those AFN ideals are implemented. Additionally, the extensive use of technological control mechanisms, aiming for complete automation, is also reminiscent of the vertical farming idea but in a more basic design here for an outdoor application. 
By their own definition, the original participatory approach of myAcker addresses pressing problems of smaller business to find technological solutions to facilitate cultivation, at the same time building strong ties with customers as part of a narrative and sales strategy. The example of the business model and findings from the empirical survey show that the implementation of ICT and elements of Smart Farming arranged according to creative systemic ideas do not, in any case, favour large enterprises. However, myAcker's influence on regional food provisioning as an alternative to the corporate food regime remains unclear, and due to the nonplace-based customers, it remains detached from regional economic cycles (cf. Klerkx et al., 2019).

Until the vegetables and herbs are sent to customers all over Austria, the customers' connection to the produce is only mediated by the web interface. However, the survey among customers showed that the gamification and simplified presentation of agricultural content does not negatively interfere with the establishment of feelings of connection and ownership to "their" produce. These feelings of connectedness culminate in defining the vegetables grown on remote plots as "their own" and "home grown" produce. This is reflected in the narratives of sustainability, traditionality, and naturalness built by company owners, which are reproduced by customers, despite the lack of real transparency concerning growing methods or evidence of the low ecological footprint of the whole operation. The felt closeness derives from the responsibility customers receive from the company, similar to the phenomenon in the solidarity economy, where emotional involvement can replace objective criteria of quality with relational qualities of ties to the producer, or, in this case, strong ties to company (and owners) and a production scheme they are part of.

The case of myAcker shows the potential of ICT and digitalisation for the realisation of hybrid, experimental concepts of food production. Different foci are possible, for example, on community aspects, gamification, automatisation, or simply the marketing or communication of business goals. However, in some future contexts, family farming structures with surplus functionality and value in surrounding areas are potentially challenged by the newly evolving business models based on technological solutions and streamlined functionalities. If there will be farms, which kind of role will future farmers play on their farm, and how can this role contribute to sensible decision-making for sustainable food production rather than reasoning emerging merely from informed machinery and "algorithmic rationality" (Miles, 2019:5)? Further exploration, therefore, needs more focus on social implications of digitalisation in agriculture by considering all the foreseeable and unforeseeable risks for current food supply systems. Especially when it comes to decisionmaking and autonomy (cf. Fielke et al., 2020; Ingram and Maye, 2020; Klerkx et al., 2019; Stock and Forney, 2014), it is worthwhile exploring societal key drivers of technologisation in agriculture. Emphasis should also be placed on the purposes of farms for their surroundings and their relationship to rural life to address the question of which implications new, high-tech supported or even autonomously operating farm systems have for rural lifestyles beyond agriculture and on human-environment relations. These fields of enquiry must be borne in mind in the course of a technological shift which may substantially change food production and the farming profession.

Data availability. Empirical data are not publicly accessible due to privacy agreements.

Author contributions. The two authors have contributed equally to the paper.

Competing interests. The authors declare that they have no conflict of interest.

Acknowledgements. We would like to thank C. and P. (name withheld) of myAcker for granting us insight into their company and our dear colleagues at our departments for helpful advice.

Review statement. This paper was edited by Myriam HoussayHolzschuch and reviewed by two anonymous referees.

\section{References}

Ash, J., Kitchin, R., and Leszczynski, A. (Eds.): Digital geographies, SAGE Publications Limited, Thousand Oaks, 2018a.

Ash, J., Kitchin, R., and Leszczynski, A.: Digital turn, digital geographies?, Prog. Human Geogr., 42, 25-43, https://doi.org/10.1177/0309132516664800, 2018b.

Balafoutis, A. T., Beck, B., Funtas, S., Tsiropoulos, Z., Vangeyte, J., van der Wal, T., Soto-Embodas, I., Gómez-Barbero, M., and Pedersen, S. M.: Smart Farming Technologies - Description, Taxonomy and Economic Impact, in: Precision Agriculture: Technology and Economic Perspectives, edited by: Pedersen, S. M. and Lind, K. M., Springer International Publishing, Cham, 21-77, 2017.

Balafoutis, A. T., van Evert, F. K., and Fountas, S.: Smart Farming Technology Trends: Economic and Environmental Effects, Labor Impact, and Adoption Readiness, Agronomy, 10, 743, https://doi.org/10.3390/agronomy10050743, 2020.

Bauriedl, S. and Strüver, A. (Eds.): Smart City - kritische Perspektiven auf die Digitalisierung in Städten, Transcript, Bielefeld, 2018.

Beacham, A. M., Vickers, L. H., and Monaghan, J. M.: Vertical farming: a summary of approaches to growing skywards, J. Horticult. Sci. Biotechnol., 94, 277-283, 2019.

Bear, C. and Holloway, L.: Country Life: Agricultural Technologies and the Emergence of New Rural Subjectivities, Geogr. Compass, 9, 303-315, https://doi.org/10.1111/gec3.12217, 2015. 
Benke, K. and Tomkins, B.: Future food-production systems: vertical farming and controlled-environment agriculture, Sustainability, 13, 13-26, https://doi.org/10.1080/15487733.2017.1394054, 2017.

Biojounaal: Online tuinplatform 'Mijn boerderijtje' gelanceerd, available at: https://www.biojournaal.nl/article/9088717/ online-tuinplatform-mijn-boerderijtje-gelanceerd/ (last access: January 2021), 2019.

Bos, E. and Owen, L.: Virtual reconnection: The online spaces of alternative food networks in England, J. Rural Stud., 45, 1-14, https://doi.org/10.1016/j.jrurstud.2016.02.016, 2016.

Bronson, K. and Knezevic, I.: Big Data in food and agriculture, Big Data Soc., 3, 1-5, https://doi.org/10.1177/2053951716648174, 2016.

Callon, M.: Society in the making: the study of technology as a tool for sociological analysis, in: The social construction of technological systems. New directions in the sociology and history of technology, edited by: Bijker, W. E., Hughes, T. P., and Pinch, T., MIT Press, Cambridge, Massachusetts, 83-103, 1987.

Dasuki, S. I., Abbott, P.: A Socio-Technical Analysis of ICT Investments in Developing Countries: A Capability Perspective, Elect. J. Inform. Syst. Dev. Countr., 67, 1-29, https://doi.org/10.1002/j.1681-4835.2015.tb00484.x, 2015.

Despommier, D.: The vertical farm: feeding the world in the 21st century, Macmillan, New York, 2010.

Ermann, U., Langthaler, E., Penker, M., and Schermer, M.: AgroFood Studies. Eine Einführung, UTB Böhlau, Vienna, 2018.

FAO: The State of Food and Agriculture, Innovation in Family Farming, Food and Agricultural Organization of the United Nations, Rome, 2014.

Fielke, S., Taylor, B., and Jakku, E.: Digitalisation of agricultural knowledge and advice networks: A state-of-the-art review, Agr. Syst. 180, 102763, https://doi.org/10.1016/j.agsy.2019.102763, 2020.

Fleming, A., Jakku, E., Lim-Camacho, L., Taylor, B., and Thorburn, P.: Is big data for big farming or for everyone? Perceptions in the Australian grains industry, Agron. Sustain. Dev., 38, 24, https://doi.org/10.1007/s13593-018-0501-y, 2018.

Forney, J.: Beyond fascinating smart tools: everyday challenges in the digitalization of agriculture, GeoAgenda, 2018/05, 10-11, 2018.

Gardena: GARDENA smart system, available at: https://www. gardena.com/int/products/smart/, last access: January 2021.

Gesing, F., Knecht, M., Flitner, M., and Amelang, K. (Eds.): NaturenKulturen, Denkräume und Werkzeuge für neue politische Ökologien, in: Edition Kulturwissenschaft, Band 146, Transcript, Bielefeld, 2019.

Gnauer, C., Pichler, H., Tauber, M., Schmittner, C., Christl, K., Knapitsch, J., and Parapatits, M.: Towards a secure and self-adapting smart indoor farming framework, Elektrotech. Inftech., 136, 341-344, https://doi.org/10.1007/s00502019-00745-0, 2019.

Goodman, D. and Dupuis, E. M.: Knowing food and growing food: beyond the production-consumption debate in the sociology of agriculture, Sociolog. Rural., 42, 5-22, https://doi.org/10.1111/1467-9523.00199, 2002.

Goodman, D., DuPuis, E. M., and Goodman, M. K.: Alternative food networks: Knowledge, practice, and politics, Oxon, Routledge, New York, 2012.
Gray, B. J. and Gibson, J. W.: Actor-Networks, Farmer Decisions, and Identity, CAFÉ, 35, 82-101, https://doi.org/10.1111/cuag.12013, 2013.

Groier, M.: Small scaled family farms in Austria, Bundesanstalt für Bauernfragen, Vienna, 2016.

Hilbert, M. and López, P.: The world's technological capacity to store, communicate, and compute information, Science, 332, 6065, https://doi.org/10.1126/science.1200970, 2011.

Holloway, L.: Virtual vegetables and adopted sheep: ethical relation, authenticity and Internet-mediated food production technologies, Area, 34, 70-81, 2002.

Ingram, J. and Maye, D.: What Are the Implications of Digitalisation for Agricultural Knowledge?, Front. Sustain. Food Syst., 4, 66, https://doi.org/10.3389/fsufs.2020.00066, 2020.

Janc, K., Czapiewski, K., and Wójcik, M.: In the starting blocks for smart agriculture: The internet as a source of knowledge in transitional agriculture, NJAS - Wageningen J. Life Sci., 90-91, 100309, https://doi.org/10.1016/j.njas.2019.100309, 2019.

Kalantari, F., Tahir, O. M., Joni, R. A., and Fatemi, E.: Opportunities and challenges in sustainability of vertical farming: A review, J. Landsc. Ecol., 11, 35-60, https://doi.org/10.1515/jlecol-20170016, 2018.

Kitchin, R., Dodge, M.: Code/space, Software and everyday life, in: Software studies, MIT Press, Cambridge, Massachusetts, 2011.

Klauser, F.: Surveillance Farm: Towards a Research Agenda on Big Data Agriculture, Surveill. Soc., 16, 370-378, https://doi.org/10.24908/ss.v16i3.12594, 2018.

Klerkx, L., Jakku, E., and Labarthe, P.: A review of social science on digital agriculture, smart farming and agriculture 4.0: New contributions and a future research agenda, NJAS - Wageningen J. Life Sci., 90-91, 100315, https://doi.org/10.1016/j.njas.2019.100315, 2019.

Kneafsey, M., Maye, D., Holloway, L., and Goodman, M. K.: Geographies of Food: An Introduction, Bloomsbury Publishing, London, 2021.

Knierim, A., Borges, F., Kernecker, M., Kraus, T., and Wurbs, A.: What drives adoption of smart farming technologies? Evidence from a cross-country study, in: Proceedings of the European International Farm Systems Association Symposium, Chania, Greece, 2018.

Knierim, A., Kernecker, M., Erdle, K., Kraus, T., Borges, F., and Wurbs, A.: Smart farming technology innovations - Insights and reflections from the German Smart-AKIS hub, NJAS - Wageningen J. Life Sci., 90-91, 100314, https://doi.org/10.1016/j.njas.2019.100314, 2019.

Kritikos, M.: Precision Agriculture in Europe: Legal, social and ethical considerations, Science and Technology Options Assessment, Scientific Foresight Unit (STOA) of the European Parliament, Brussels, 2017.

Kropp, C.: Intelligente Städte. Rationalität, Einfluss und Legitimation von Algorithmen, in: Smart City - kritische Perspektiven auf die Digitalisierung in Städten, edited by: Bauriedl, S. and Strüver, A., Transcript, 33-42, Bielefeld, 2018.

Latour, B: Eine neue Soziologie für eine neue Gesellschaft, Suhrkamp, Frankfurt am Main, 2007.

Lioutas, E. D., Charatsari, C., La Rocca, G., and De Rosa, M.: Key questions on the use of big data in farming: An activity theory approach, NJAS - Wageningen J. Life Sci., 90-91, 100297, https://doi.org/10.1016/j.njas.2019.04.003, 2019. 
Lombardi, P. and Vanolo, A.: Smart City as a Mobile Technology: Critical Perspectives on Urban Development Policies, in: Transforming City Governments for Successful Smart Cities, Public Administration and Information Technology, Vol. 8, edited by: Rodríguez-Bolívar, M., Springer, Cham, 147-161, 2015.

Lowder, S. K., Skoet, J., and Raney, T.: The Number, Size, and Distribution of Farms, Smallholder Farms, and Family Farms Worldwide, World Dev., 87, 16-29, https://doi.org/10.1016/j.worlddev.2015.10.041, 2016.

Martin, J., Torres, D., Fernandez, A., Pravisani, S., and Briend, G.: Using Citizen Science Gamification in Agriculture Collaborative Knowledge Production, in: Proceedings of the XIX International Conference on Human Computer Interaction (Interacción 2018), Association for Computing Machinery, New York, 1-8, 2018.

Michel-Villarreal, R., Hingley, M., and Bregoli, I.: Defining alternative food networks: A systematic literature review, In: International Food Marketing Research Symposium, June 2018, University of Bournemouth, Bournemouth, UK, 2018.

Miles, C.: The combine will tell the truth: On precision agriculture and algorithmic rationality, Big Data Soc., 6, 1-12, https://doi.org/10.1177/2053951719849444, 2019.

Murdoch, J.: Inhuman/nonhuman/human: Actor-network theory and the prospects for a nondualistic and symmetrical perspective on nature and society, Environ. Plnn. D, 15, 731-756, https://doi.org/10.1068/d150731, 1997.

Murdoch, J.: Networking Rurality: Emergent Complexity in the Countryside, in: The Handbook of Rural Studies, SAGE Publications Ltd, London, 171-184, https://doi.org/10.4135/9781848608016.n12, 2006.

Murgante, B. and Borruso, G.: Cities and Smartness: A Critical Analysis of Opportunities and Risks, in: Computational Science and Its Applications, edited by: Hutchison, D., Kanade, T., Kittler, J., Kleinberg, J. M., Mattern, F., and Mitchell, J. C., Heidelberg, Springer, 630-642, 2013.

Musik, C. and Bogner, A. (Eds.): Digitalization \& society. A sociology of technology perspective on current trends in data, digital security and the internet, in: Österreichische Zeitschrift für Soziologie, Sonderheft 44, Springer, Heidelberg, 2019.

MyAcker: https://myacker.com/de, last access: 18 February 2021.

Nevado-Peña, D., López-Ruiz, V., and Alfaro-Navarro, J.-L.: Improving quality of life perception with ICT use and technological capacity in Europe, Technol. Forecast. Social Change, 148, 119734, https://doi.org/10.1016/j.techfore.2019.119734, 2019.

Paniagua, A.: Sustainable Geographical Changes in Rural Areas: Key Paths, Orientations and Limits, Sustainability, 13, 2059, https://doi.org/10.3390/su13042059, 2021.

Pedersen, S. M. and Lind, K. M. (Eds.): Precision Agriculture: Technology and Economic Perspectives, Springer International Publishing, Cham, 2017.

Plank, C., Hafner, R., and Stotten, R.: Analyzing values-based modes of production and consumption: Community-supported agriculture in the Austrian Third Food Regime, Österr. Z. Soziol., 45, 49-68, https://doi.org/10.1007/s11614-020-00393-1, 2020.

Randelli, F. and Rocchi, B.: Analysing the role of consumers within technological innovation systems: The case of alternative food networks, Environ. Innov. Societ. Trans., 25, 94-106, 2017.

Redepenning, M.: Die Komplexität des Landes - neue Bedeutungen des Ländlichen im Zuge der Counterurbanisierung, Zeitschrift für Agrargeschichte und Agrarsoziologie, ZAA 57, 46-56, 2009.
Renting, H., Marsden, T. K., and Banks, J.: Understanding Alternative Food Networks: Exploring the Role of Short Food Supply Chains in Rural Development, Environ. Plan. A, 35, 393-411, https://doi.org/10.1068/a3510, 2003.

Sharifi, A.: A critical review of selected smart city assessment tools and indicator sets, J. Clean. Prod., 233, 1269-1283, https://doi.org/10.1016/j.jclepro.2019.06.172, 2019.

Sinabell, F.: Die Multifunktionalität der österreichischen Landwirtschaft - eine ökonomische Annäherung (the multifunctionality of agriculture in Austria - an economic approach), in: Dokumentation der 11. ÖGA-Jahrestagung an der Karl-FranzensUniversität Graz, 27 and 28 September 2001, edited by: Penker, M. and Pfusterschmid, S., Facultas Verlag, Vienna, 245-252, 2003.

Sørensen, C. A. G., Kateris, D., and Bochtis, D.: ICT Innovations and Smart Farming, in: Information and Communication Technologies in Modern Agricultural Development, 8th International Conference, HAICTA 2017, Chania, 21-24 September 2017, Crete, Greece, Revised Selected Papers, Vol. 953, edited by: Salampasis, M. and Bournaris, T., Springer International Publishing, Cham, 1-19, 2019.

Statistik Austria: Agrarstrukturerhebung 2016, Land- und forstwirtschaftliche Betriebe in Österreich 1951 bis 2016, available at: http://www.statistik.at/web_de/statistiken/wirtschaft/ land_und_forstwirtschaft/agrarstruktur_flaechen_ertraege/ betriebsstruktur/index.html (last access: 10 February 2021), 2016.

Stock, P. V. and Forney, J.: Farmer autonomy and the farming self, J. Rural Stud., 36, 160-171, https://doi.org/10.1016/j.jrurstud.2014.07.004, 2014.

Szilágyi, R., Kovács, T., Nagy, K., and Várallyai, L.: Development of Farm simulation application, an example for gamification in higher education, J. Agricult. Inform., 8, 12-21, https://doi.org/10.17700/jai.2017.8.2.373, 2017.

Thapa, D. and Saebø, Ø.: Exploring the Link between ICT and Development in the Context of Developing Countries: A Literature Review, Elect. J. Inform. Syst. Dev. Countr., 64, 1-15, https://doi.org/10.1002/j.1681-4835.2014.tb00454.x, 2014.

Tsouvalis, J., Seymour, S., and Watkins, C.: Exploring KnowledgeCultures: Precision Farming, Yield Mapping, and the Expert-Farmer Interface, Environ. Plan. A, 32, 909-924, https://doi.org/10.1068/a32138, 2000.

van der Burg, S., Bogaardt, M. J., and Wolfert, S.: Ethics of smart farming: Current questions and directions for responsible innovation towards the future, NJAS - Wageningen J. Life Sci., 90-91, 100289, https://doi.org/10.1016/j.njas.2019.01.001, 2019.

van Huylenbroeck, G., Vandermeulen, V., Mettepenningen, E., and Verspecht, A.: Multifunctionality of Agriculture: A Review of Definitions, Evidence and Instruments, Living Rev. Landsc. Res., 1, 1-43, https://doi.org/10.12942/lrlr-2007-3, 2007.

Varga, M.: From the Qualities of Products to the Qualities of Relations: Value Conventions in the Solidarity Economy in Sicily, Valuat. Stud., 6, 63-86, https://doi.org/10.3384/VS.20015992.196163, 2019.

Walter, A., Finger, R., Huber, R., and Buchmann, N.: Opinion: Smart farming is key to developing sustainable agriculture, P. Natl. Acad. Sci. USA, 114, 6148-6150, https://doi.org/10.1073/pnas.1707462114, 2017. 
Whatmore, S.: Hybrid Geographies: Rethinking the 'Human' in $\mathrm{Hu}-$ man Geography Today, Polity Press, Cambridge, UK, 1999.

Wilson, G. A.: From productivism to post-productivism... and back again? Exploring the (un)changed natural and mental landscapes of European agriculture, T. I. Brit. Geogr., 26, 77-102, 2001.
Winter, M.: Geographies of food: agro-food geographies making reconnections, Prog. Human Geogr., 27, 505-513, https://doi.org/10.1191/0309132503ph446pr, 2003.

Zambon, I., Cecchini, M., Egidi, G., Saporito, M. G., and Colantoni, A.: Revolution 4.0: Industry vs. Agriculture in a Future Development for SMEs, Processes, 7, 36, https://doi.org/10.3390/pr7010036, 2019. 